\title{
Psychological Correlates of Substance Abuse among First-admission Patients with Substance Use Disorders
}

\author{
Dr. Satyananda Panda ${ }^{1}$
}

\section{ABSTRACT}

The aim of the present study was to investigate psychological correlates of substance abuse among first-admission male and female patients diagnosed with substance use disorders. Data was collected from a sample of 60 (30 male and 30 female) first-admitted patients with substance use disorders (SUDs), with no previous history of specialized treatment (addiction clinics, psychiatry). Substance use disorders were diagnosed according to DSM-V. Patients were assessed with Beck Depression Inventory and Eysenck Personality Questionnaire- Revised (EPQ-R). The statistical analysis indicated that depression did not correlate with psychoticism ( $\mathrm{r}$ $=-.062$ ). There existed a negative and significant correlation between depression and extraversion ( $\mathrm{r}=-.68, \mathrm{p}<.01$ ). There also existed a negative and significant correlation between extraversion and neuroticism $(\mathrm{r}=-.601, \mathrm{p}<.01)$. Neuroticism correlated with depression positively and significantly $(\mathrm{r}=.59, \mathrm{p}<.01)$. There was no significant difference found between hospitalized male and female patients with substance abuse disorders on different psychological variables like depression, psychoticism, and neuroticism. However, a significant difference among them was found on extraversion $(\mathrm{t}=3.17, \mathrm{p}<.01)$. Depression and personality traits still may have some role in the etiology of substance use disorder and may act either as predisposing, precipitating or perpetuating factors. So, depression and personality traits of a person should be considered during treatment, management, prevention and rehabilitation of the patients with substance use disorder.

Keywords: Substance Abuse, Depression, Neuroticism, Personality Traits, Substance Use Disorders.

Substance abuse refers to the maladaptive pattern of substance use that results in repeated, significant adverse effects and maladaptive behaviours: failure to meet obligations at work, in school, or at home; repeated use of psychoactive substance in hazardous ways; recurrent legal problems related to the substance; and continued use of the substance despite its negative effects on social relationships (Baron, 2008).It is also known as drug abuse and substance use disorder. In the fifth addition of the Diagnostic and Statistical Manual of Mental Disorders (2013), the revised chapter of "Substance-Related and Addictive Disorders" includes substantive changes to the disorders grouped plus changes to the criteria of certain conditions. The DSM-5 Substance-

\footnotetext{
${ }^{1}$ Assistant Professor, Department of Psychology, Sikkim University, Gangtok (Sikkim) (C) 2015 I S Panda; licensee IJIP. This is an Open Access Research distributed under the terms of the Creative Commons Attribution License (http://creativecommons.org/licenses/by/2.0), which permits unrestricted use, distribution, and reproduction in any Medium, provided the original work is properly cited.
} 


\section{Psychological Correlates of Substance Abuse among First-admission Patients with Substance Use Disorders}

Related Disorders Work Group has proposed eliminating two categories in the current DSM-IV. Substance use disorder in the DSM-5 combines the DSM-IV categories of substance abuse and substance dependence into a single disorder measured on a continuum from mild to severe (APA, 2013).

Changes in women's social role over the past years likely influenced the gender gap in substance use and substance related disorders, with potentially significant prevention and treatment implications. Male to female ratios of prevalence estimates of substance use are narrowing in different countries. The initiation of substance use is progressively taking place at younger ages, the trend being more dramatic among women as compared to men. Women's accelerated progression to dependence (so called "telescoping effect") is a robust finding among alcohol dependent individuals, although the effect seems to be weaker among younger individuals (Zilberman et al., 2008).

Wise, Miller and Preussler (2003) conducted a study to determine if there is a relationship between depression and alcohol/substance use in a rural population in the Midwestern United States. In a case control design, those who reported alcohol use or alcohol use with other substance use were found to score significantly higher on the depression scale than those who reported no alcohol or substance use, although the effect sizes were small. It was found that males and females who reported alcohol use only did not differ significantly on the depression scale.

Cuomoa et al. (2008) did a study to analyze psychological and judicial features of a subgroup of inmates with substance abuse. Substance abusers had on average multiple incarcerations (78.8\%), more juvenile convictions (60.2\%), more violent behaviors during detention (29.8\%), and a history of one or more suicide attempts (20.8\%). They also had higher scores on subscales for childhood trauma, higher scores for psychoticism and neuroticism, higher impulsivity levels, worse resilience, increased hostility, and prevalent suicidal ideation.

Dubey et al. (2010) conducted a study to investigate the personality traits of substance abusers as compared with non-substance abusers by using the NEO-Five Factor Inventory. It was found that substance abused group scored higher on Neuroticism and Extraversion dimensions, whereas non-substance abusers significantly scored higher on Openness and Conscientiousness dimensions of Big-Five. No significant difference was obtained on Agreeableness domain of personality.

Substance abuse has traditionally been prevalent among Sikkimese population. From their observation substance abuse is more common in rural areas basically alcohol than the urban areas which is negatively related to level of education and socio economic condition. State Socio Economic Census (2006) of Department of Economics \& Statistics Monitoring \& Evaluation 


\section{Psychological Correlates of Substance Abuse among First-admission Patients with Substance Use Disorders}

(DESME) has shown that prevalence of alcohol use in Sikkim is $37.57 \%$ and $556.92 \%$ in urban and rural continuum. Emergency services utilization by substance abusers is one of the sources and indicators of assessing problematic substance use. It is an important measure to assess treatment demand from substance abusers and can be an effective tool for an assessment of psycho-social causes, magnitude and pattern of substance abuse in the community. Therefore, collecting information of substance abusers in the hospital setting would serve as a tool to have an idea about the psychological causes and nature of substance abuse in the community. It will help to understand the basic psychotic problems arising from different substance use. Keeping in mind the review of related literature, the aim of the present study is to investigate on psychological correlates of substance abuse among hospitalized male and female substance abusers.

\section{OBJECTIVES}

1. To find out the correlation between depression and personality traits (i.e. Psychoticism, Extraversion and Neuroticism) among hospitalized male and female substance abusers.

2. To find out the significant difference between hospitalized male and female substance abusers on depression.

3. To find out the significant difference between hospitalized male and female substance abusers on psychoticism.

4. To find out the significant difference between hospitalized male and female substance abusers on extraversion.

5. To find out the significant difference between hospitalized male and female substance abusers on neuroticism.

\section{HYPOTHESES}

1. Positive and significant correlation will exist between Depression and Personality traits (i.e. Psychoticism, Extraversion and Neuroticism) among hospitalized male and female substance abusers.

2. There will be no significant difference between hospitalized male and female substance abusers on Depression.

3. There will be no significant difference between hospitalized male and female substance abusers on Psychoticism.

4. There will be no significant difference between hospitalized male and female substance abusers on Extraversion.

5. There will be no significant difference between hospitalized male and female substance abusers on Neuroticism.

\section{METHOD}

For the present study, 60 participants were taken which included 30 males and 30 females of age 19-55 years, admitted to Detoxification and Rehabilitation Centre, 32 mile, Sikkim. Stratified random sampling was employed for the purpose of data collection. The mean age of male and female hospitalized substance abusers was 32.5. 


\section{Psychological Correlates of Substance Abuse among First-admission Patients with Substance Use Disorders}

Inclusion Criteria:(a)Patients hospitalized since maximum last 10 days; (b) Patients who are first time admitted cases; (c) Substance abusers i.e. alcohol and other substances like opium, counter drug, marijuana; (d) Males and Females; (e) Rural and Urban areas; (f) Both Educated and Uneducated; (g) All religion; (h) Lower, middle, and upper economic class.

Exclusion Criteria:(a)Patients having any psychiatric disorders; (b) Patients not willing to participate; (c) Patients with major physical diseases.

The following psychological tools were used for the purpose of collection of data:

1. The Beck Depression Inventory (Beck, Steer \& Brown, 1996): The Beck Depression Inventory is a widely utilized 21-item self-report scale in both clinical and research studies (Beck, Steer \& Brown, 1996). The Beck Depression Inventory-II is a depression rating scale that can be used in individuals that are ages 13 years and older, and rates symptoms of depression in terms of severity on a scale from 0 to 3 based on the 21 specific items. The test-retest reliability for BDIII was 0.93 .

2. The Eysenck Personality Questionnaire-Revised (Eysenck, 1991):EPQ-R is the result of many years of developmental work. It was designed to give rough and ready measure of three important personality dimensions: psychoticism, extraversion, and neuroticism. Each of these three traits are measured by means of 100 questions, carefully selected after lengthy item analysis and factor analysis.

Procedure: For the collection of data, a prior permission was sought from the director of Rehabilitation Centre. The participants were explained the purpose of the present study and data was then collected individually. It was made sure that the participants understood the instruction properly and after assurance both the questionnaires (Beck Depression Inventory-II and Eysenck Personality Questionnaire-R) were handed out to the participants and no time limit was given. In order to present data in more intelligible and interpreted form the investigator used Statistical Package for Social Science (SPSS) version 22. Descriptive statistics like percentage, mean and standard deviation was also used. Data was also calculated using Pearson's co-efficient correlation and t-test.

\section{RESULTS AND DISCUSSION}

In order to test various hypotheses put forward, the following analysis was carried out.

Table 1: Correlation Matrix $(\mathrm{N}=60)$

\begin{tabular}{|c|c|c|c|c|}
\hline Variables & Depression & Psychoticism & Extraversion & Neuroticism \\
\hline Depression & - & -.062 & $-.679 * *$ & $.591 * *$ \\
\hline Psychoticism & - & - & .159 & -.143 \\
\hline Extraversion & - & - & - & $-.601^{* *}$ \\
\hline Neuroticism & - & - & - & - \\
\hline
\end{tabular}




\section{Psychological Correlates of Substance Abuse among First-admission Patients with Substance Use Disorders}

Table 1 shows that depression is not correlated with psychoticism $(r=-.062)$ which suggests that depression has no relationship with psychoticism. The table also shows that depression is negatively correlated with extraversion $(r=-.679)$ at 0.01 level which suggests that as the depression level in a person increases, the out-going and social nature of a person decreases. In other words, it can be interpreted that person with introvert personality trait may have depression and vice versa. There also exists a negative and significant correlation between extraversion and neuroticism ( $r=-.601$ : negatively significant at 0.01 level). It can also be seen from Table 1 that neuroticism is correlated with depression positively and significantly at 0.01 level $(\mathrm{r}=.591)$. This means that as the level of depression increases, neuroticism level also increases. Neuroticism refers to a tendency to experience negative affect and therefore this positive correlation of neuroticism with depression is not surprising which have been supported by the previous findings. Longitudinal studies (Hirschfeld et al., 1989) have found that high pre-morbid neuroticism is positively associated with the development of depression.

Thus, the first hypothesis of the study "there will be positive and significant correlation between depression and personality traits (i.e. Psychoticism, Extraversion and Neuroticism) among hospitalized male and female substance abusers" has not been retained. The result shows positive correlation between depression and just one dimension of personality i.e. neuroticism.

Table 2: Mean, Standard Deviation and t test of hospitalized male and female substance abusers on Depression ( $\mathrm{N}=6 \mathbf{6 0})$

\begin{tabular}{|c|c|c|c|c|c|}
\hline Gender & $\mathrm{N}$ & Mean & $\mathrm{SD}$ & $\mathrm{t}-$ Value & Sig./Non-Sig. $(\mathrm{df}=58)$ \\
\hline Male & 30 & 24.27 & 11.38 & -1.732 & .081 (Non-sig.) \\
\hline Female & 30 & 29.93 & 13.85 & & \\
\hline
\end{tabular}

Table 2 shows the mean scores of hospitalized male and female substance abusers which are 24.27 and 29.93 respectively. The t-test of both males and females is -1.732 with the significant value of .081 which is not significant. This means that there is no significant difference between hospitalized male and female substance abusers on depression, thus, retaining the first hypothesis of the study "there will be no significant difference between hospitalized male and female substance abusers on depression." However, since the mean value of female substance abusers is greater than that of males, it indicates that females tend to be more depressed than males. The reason could be that females are sensitive beings and report feeling shame or embarrassment because they are in substance abuse treatment in a small conservative place like Sikkim which in turn result in feeling worthless and depressed. Women are more likely to become depressed in response to stressful events like a death in the family, difficult relationship, or a failed job and they tend to respond in ways that prolong their stress more so than men do. It was found that anxiety and depressive disorders tend to be more prevalent and severe among women (Brady \& Randall, 1999). 
Table 3: Mean, Standard Deviation and test of hospitalized male and female substance abusers on Psychoticism(N=60)

\begin{tabular}{|l|c|c|c|c|c|}
\hline Gender & $\mathrm{N}$ & Mean & S.D. & $\mathrm{t}-$ Value & Sig./Non-sig. \\
\hline Male & 30 & 7.67 & 2.78 & .443 & 0.680 (Non-sig) \\
\hline Female & 30 & 7.37 & 2.47 & & \\
\hline
\end{tabular}

Table 3 shows the mean score of hospitalized male and female substance abusers which is 7.67 and females, 7.37 . The t-test is .443 with the significant value of .680 which is not significant. This means that there is no significant difference between male and female substance abusers on psychoticism. This retains the second hypothesis of the study "there will be no significant difference between hospitalized male and female substance abusers on psychoticism.” However, since the mean value of males is greater than that of females, it indicates that male substance abusers are slightly higher on psychoticism as compared to female substance abusers which describes the personality as solitary, troublesome, cruel, and lacking in feeling and empathy, hostile to others, sensation seeking, and liking odd and unusual things. This finding is supported by a study conducted by Austin et al. (2001) where it was found that males scored significantly higher than females on psychoticism. Biological differences between males and females interacting with the predisposing factors that may in turn be influenced by social and cultural factors may explain differences in psychosis between males and females. Females are by nature sensitive, soft, and vulnerable beings which go against the characteristics of psychoticism.

Table 4: Mean, Standard Deviation and test of hospitalized male and female substance abusers on Extraversion $(\mathbf{N}=60)$

\begin{tabular}{|l|c|c|c|c|c|}
\hline Gender & $\mathrm{N}$ & Mean & Std. Deviation & t- Value & Sig./Non.sig. \\
\hline Male & 30 & 13.73 & 3.02 & 3.17 & .000 (Sig.) \\
\hline Female & 30 & 9.47 & 6.72 & & \\
\hline
\end{tabular}

Table 4shows the mean scores of hospitalized male and female substance abusers which are 13.73 and 9.47 respectively. The t-test of both males and females is 3.17 with the significant value of .000 which is significant at 0.01 level. This means that there is a significant difference between male and female substance abusers on extraversion. Thus, the third hypothesis of the study "there will be no significant difference between hospitalized male and female substance abusers on extraversion" has not been retained. The result shows that male substance abusers are more out-going and social as compared to female substance abusers and is evident from their mean scores where males have greater score. This could be due to males playing a dominant role in the society where females are still suppressed and not allowed their freedom of speech and expression. 
Table 5: Mean, Standard Deviation and test of hospitalized male and female substance abusers on Neuroticism( $\mathbf{N}=60)$

\begin{tabular}{|l|c|c|c|c|c|}
\hline Gender & $\mathrm{N}$ & Mean & Std. Deviation & t- Value & Sig./Non.sig. \\
\hline Male & 30 & 13.27 & 3.70 & -3.83 & sig.) \\
\hline Female & 30 & 17.33 & 4.48 & & \\
\hline
\end{tabular}

Table 5 shows the mean scores of hospitalized male and female substance abusers which are 13.27 and 17.33 respectively. The t-test of both males and females is -3.83 with the significant value of .385 which is not significant. This means that there is no significant difference between male and female substance abusers on neuroticism. Thus, the fourth hypothesis of the study "there will be no significant difference between hospitalized male and female substance abusers on neuroticism" has been retained. The result shows that female substance abusers are higher on neuroticism as compared to male substance abusers and is evident from their mean scores where females have greater score. Neuroticism reflects level of emotional adjustment and instability. This finding is supported by a study by Austin et al. (2001) where it was found that females scored significantly higher than males on neuroticism.

\section{CONCLUSION}

Results of the present study show that no correlation was found to exist between depression and psychoticism among hospitalized male and female substance abusers. There was a negative correlation between depression and extraversion. Depression was found to be positively correlated with neuroticism among hospitalized male and female substance abusers. There is no significant difference between hospitalized male and female substance abusers on depression though female scored higher on depression than males. Among the dimensions of personality, psychoticism was higher in male substance abusers than females but they did not differ significantly on this dimension. On extraversion, there seem to be a significant difference between male and female substance abusers rejecting one of the hypotheses of the study. It was also found that males were more extraverted than females. On neuroticism, no significant difference was found. However, female substance abusers scored higher on it than males.

\section{SUGGESTIONS FOR FUTURE RESEARCH}

1. Depression and personality traits may have some role in the etiology of substance use disorder and may act either as predisposing, precipitating or perpetuating factors. So personality traits of a person should be considered during treatment, management, prevention and rehabilitation of the patients with substance use disorder.

2. A cross-sectional study examining substance abuse among various age groups can also be conducted. 


\section{Psychological Correlates of Substance Abuse among First-admission Patients with Substance Use Disorders}

3. A large-scale, longitudinal study among substance users of both sexes may be undertaken in our state.

4. Use of substances among different communities and also among different religious sects to see which community and religious sect uses substances more often.

\section{REFERENCES}

American Psychiatric Association (2013). Diagnostic and Statistical Manual of Mental Disorders (5th ed.). Arlington, VA: American Psychiatric Publishing.

Austin, E. J., Manning, J. T., McInroy, K., \& Matthews, E. (2001).A preliminary investigation of the associations between personality, cognitive ability and digit ratio.Personality and Individual Differences, 33, 1115-1124.

Baron, R.A. (2008). Psychology (5th ed.). Delhi: Prentice Hall of India.

Beck, A.T., Steer, R.A., \& Brown, G.K. (1996). Manual for the Beck Depression InventoryII. San Antonio, TX: Psychological Corporation.

Brady, K. T., \& Randall, C. L. (1999). Gender differences in substance use disorder. The Psychiatric Clinics of North America, 22(2), 241-52.

Cuomoa, C., Sarchiaponea, M., Giannantoniob, M. D., Mancinic, M., \&Royd, A. (2008).Aggression, Impulsivity, Personality Traits, and Childhood Trauma of Prisoners with Substance Abuse and Addiction.The American Journal of Drug and Alcohol Abuse, 34(3), 339-345.

Dubey, C., Arora, M., Gupta, S., Kumar, B. (2010). Factor Correlates: A Comparison of Substance Abusers and Non-Substance Abusers. Journal of the Indian Academy of Applied Psychology, 36(1), 107-114.

Eysenck, H. J. (1991). Dimensions of personality: 16, 5, or 3-Criteria for a taxonomic paradigm. Personality and Individual Differences, 12, 773-790.

Hirschfeld, R. M. A., Klerman, G. L., \&Lavori, P. ( 1989) Premorbid personality assessments of first onset of major depression. Archives of General Psychiatry, 46, 345 -350.

Wise, J. M., Miller, R. E., \&Preussler, D. W. (2003). The Relationship between Depression and Alcohol / Substance Use in the Rural Midwestern United States.Journal of Rural Community Psychology, E6(2).

Zilberman, M., Tavares, H., \& El-Guebaly, N. (2008).Gender Similarities and Differences.Journal of Addictive Diseases, 22(4), 61-74. 